\title{
Study on College Physical Education based on Hierarchical Teaching Model
}

\author{
Ruilin Liang \\ College of Physical Education, Linyi University, \\ Linyi 276005, Shandong Province
}

\begin{abstract}
Along with the constant improvement of China's economic development, the quality-oriented education reform is being greatly implemented, in which training the high-quality talents with an all-round moral, intellectual, and physical development is the goal. The development of the physical education can not only improve the students' physical fitness, but also steel the students' will and enhance the physical quality. However, the traditional teaching method is always used by colleges and universities for physical education, and then, the enthusiasm of student is not fully aroused; sport items are simple and the infrastructure is imperfect. As a result, the development of physical education is affected. The hierarchical teaching model can be implemented for teaching students according to their aptitude; exercises are provided in combination with different physical conditions of students, aiming to improve the teaching effectiveness. In this paper, the problems and countermeasures of physical education in colleges and universities are discussed in combination with the hierarchical teaching model.
\end{abstract}

Keywords- Hierarchical Teaching Model; Physical Education; Quality-oriented Education

\section{Introduction}

For a long time, teaching students according to their aptitude is always a teaching idea and goal followed and pursued by colleges and universities. However, this concept has been difficult to implement in colleges and universities, because cooperation in every aspect is short. Hierarchical teaching model is a teaching model to rise in recent years, which is the creation and improvement of the traditional teaching model for the past. In view of the current problems in the hierarchical teaching value strategies and implementation, wrong practice and enlightenment emerge. By enhancing and improving the hierarchical teaching, the key problems of the teaching model are found, and this is of important significance to the optimization of the hierarchical teaching.

2. The significance of applying the hierarchical teaching model to the physical education in colleges and universities

In the process of applying the hierarchical teaching model, different teaching methods are adopted according to the students' individual differences; the students' individual difference is respected; different layers are divided by oriented at all the students; the teaching requirements are raised, and teaching contents and learning styles are designed, so as to promote students to find interest in learning and enhance learning confidence. In recent years, the hierarchical teaching method is adopted by many colleges and universities, and this practice is of great significance to the optimization of the teaching reform and also brings forth new ideas into the physical educational mode.

\subsection{Making the classroom teaching efficiency improved and realizing the educational objective of comprehensive development}

The educational objective of comprehensive development contains two meanings. First, all students are regarded as the targets to provide them with a fair, comfortable, superior development platform, create development opportunities, and promote them to play their 
ability and realize the balanced development. The comprehensive development does not mean the blind pursuit of development, and its focus lies in reflecting the balanced development and realizing the development in every aspect. Second, individuality is combined with the comprehensive development; each student can get more development opportunities based on the basic quality training, acquire different interests, and reflect the differences of development and the individuality. This is not an extreme, partial development, but the quality in all aspects is in a balanced development. Therefore, the quality-oriented education is not necessarily high quality education, and individuality education is necessarily developing in a dynamic environment, so as to reflect the high quality education [1].

\subsection{Promoting the students' affective development, forming social and economic culture and developing personality traits}

At present, the society is in a rapid transformation: economic transformation, knowledge transformation, and cultural transformation from the "single" culture in the past to the current "pluralism" culture. Compared with industrial economy and planned economy in the past, the knowledge economy possesses greater potential and is a representative of the innovative economy, and it raises higher requirements for people's innovation capability and personality development. Therefore, independent will is necessarily combined with a good moral character; the previous "scholasticism", "rigid" and "inflexible" pattern is changed to flexible, diverse learning style. Along with the advance of the social transformation, the traditional "single" culture pattern can be broken on the basis of concluding previous experience and theories, aiming to open up an equal, harmonious, and mutually respected cultural pattern. Economic and cultural development requirements have inherent contradictions with the inherent teaching system, and therefore, the existing teaching system is necessarily reformed and optimized and diversified and individualized teaching system construction is supported [2].

\subsection{Producing important significance to training the students' interest}

Interest is the best teacher. In the existing educational idea, high importance is attached to "maintaining and improving the quality of individuals and social life"; the goal is never achieved only by the knowledge and skills learning during the schooling period; a lifelong learning goal is necessarily established. Learning does not end with the completion of PE courses; another learning area is opened up to realize the sustainable development of individual learning. Individual learning includes three aspects: basic knowledge, learning interest, and learning method. In table 1 and table 2, a survey on the physical education of a college is shown, which can reflect the change from concept to reality. "Health physical education" grows to be an important part affecting the idea about physical education.

Table 1: Training contents emphasized by college PE teachers

\begin{tabular}{ccccc}
\hline Content & $\begin{array}{c}\text { Initiative } \\
\text { Spirit }\end{array}$ & Practical Ability & Hobbies and Interests & $\begin{array}{c}\text { Awareness of } \\
\text { Training }\end{array}$ \\
\hline Percentage (\%) & $22 \%$ & $65 \%$ & $50 \%$ & $45 \%$ \\
\hline
\end{tabular}

Table 2: Contents acquired by college students in hierarchical PE teaching model

\begin{tabular}{ccccccc}
\hline Content & $\begin{array}{c}\text { Get } \\
\text { interest }\end{array}$ & $\begin{array}{c}\text { Learn } \\
\text { Knowledge }\end{array}$ & $\begin{array}{c}\text { Find } \\
\text { Interest }\end{array}$ & $\begin{array}{c}\text { Change } \\
\text { Attitude }\end{array}$ & $\begin{array}{c}\text { Set up } \\
\text { habits }\end{array}$ & $\begin{array}{c}\text { Master } \\
\text { skills }\end{array}$ \\
\hline Percentage (\%) & 51.2 & 53.6 & 38.5 & 22 & 27.4 & 40.6 \\
\hline
\end{tabular}




\section{The principles of hierarchical teaching}

\subsection{The principle of differentiation}

The principle of differentiation is to respect the students' individual difference, and this is an important part of teaching students according to their aptitude. Therefore, in the application of the hierarchical teaching model, it is necessary to correctly understand, use and eliminate the differences, and then the students' individual development will be more effective; the quality of individual development is improved.

\subsection{The principle of reasonableness}

In the hierarchical teaching, an equal, democratic and harmonious relationship between teachers and students is required to establish; diverse teaching methods are used for providing the students with independent and different thinking space, aiming to create more opportunities to study and promote students to be dominant in learning [3].

\subsection{The principle of inspiration}

Every student is eager for success and hopes to be praised and trusted. This is also the foundation for excavating the students' potential. In the teaching, teachers need to hold a positive attitude toward students, encourage students to carry out exploration and innovation, and create opportunities for students to probe and discover knowledge.

\section{Problems in the practice of the hierarchical teaching model}

\subsection{Hierarchical solidification}

In accordance with the relevant specifications, students are grouped. This is the starting point of the hierarchical teaching model. The hierarchical purpose is to distinguish the differences of students and promote targeted and adaptable teaching to effectively develop, and improve the teaching efficiency. But the students' sports skills are constantly adjusting and changing, and their interest, achievements and skills will also vary along with the implementation of the hierarchical teaching model. For example, the psychological changes such as "upset", "depression", and "dissatisfaction" emerge, and the traditional hierarchical teaching method will be inapplicable [4]. Thus, "positioning" or adjustment is necessarily made according to the skills and amplitude, to meet the hierarchical requirements and conform to the "elastic layered" requirements.

\subsection{Expanding hierarchical teaching objectives}

In the hierarchical teaching model, individual differences and the development levels of students are usually stressed; teaching content and practice task are designed according to different levels of students to achieve the teaching objectives. Thus, the students at each level can keep a good state of mind and realize the vertical development. From the long-term development, this model is not known well. As the teaching objectives or differences are expanded, the requirements for some students are lowered, but this becomes an excuse for the decline of the students' performance. For the students in the same age or grade, they are different in PE knowledge, skills, and physical condition. Therefore, it is seen that there are obvious differences in the hierarchical teaching, so that the students at the low level recognize the knowledge shallowly and practice less; the primary hierarchy is determined as the target skill and this goes against the purpose of the hierarchical teaching and the realistic hierarchical teaching direction.

\subsection{Distorted evaluation on hierarchical students}

In teaching activities, the evaluation on students is an indispensable part. Student evaluation function is divided into the following types: to understand somewhat about the starting point of learning; to evaluate the learning results; to let teachers recognize the primary and secondary 
teaching points and timely help the students stricken by learning difficulties in order to stimulate the students' learning potential. In the hierarchical teaching practice of many colleges and universities, the effect from the traditional teaching model is deeper and the effective evaluation methods are not used, and distortion even appears - the same evaluation criteria is used as index for the evaluation on different levels. The hierarchical evaluation method is applied by some schools, but the evaluation results are different from the different levels.

\section{The strategies for the optimization of the hierarchical evaluation model}

\subsection{Combining hierarchy with differences}

The students are in the principal position of the teaching, but teachers still play an irreplaceable role in teaching and better provide students with guidance and arrangement as a whole. Thus, teachers are required to understand the differences of the students, and then, the hierarchical teaching can be implemented in a targeted way according to the "idea of teaching students according to their aptitude". Thus, it is seen that to clearly define the standards for leveling the students is very necessary in the hierarchical teaching. In view of the differences between students, clear and explicit definition is more difficult to provide. Therefore, physical exercises levels are not used as the bases to divide the levels of students; the leveling standards for students are determined after the differences between students are comprehensively analyzed.

First, the hierarchical teaching objectives are made in accordance with the students' individual differences, quality, and testing sports scores, so as to evaluate the teaching levels and then carry out the hierarchical teaching. In the selection of the teaching methods, the selective courses are combined with the guidance of teachers, which can be accepted by most students.

\subsection{Combining the hierarchical teaching with the individual guidance}

In order to prevent the disadvantages of the traditional teaching model to emerge in the hierarchical teaching model, the problems or learning difficulties that students may encounter at the classroom are predicted on the before-class preparation. Second, to respect differences and pay attention to the overall effect is to prevent the different changes of the students at different levels. Again, a "recent development zone" is necessarily constructed when different students' learning goals are divided, aiming to improve the teachers' competence in observation and analysis and promote students to achieve comprehensive development and progress [5].

\subsection{Combining results with the evaluation process}

A scientific, reasonable physical education hierarchical teaching evaluation method is of important significance to the implementation of hierarchical teaching, but also an important content of teaching reform. In the hierarchical teaching model, the teaching progress can be enhanced according to the students' differences and learning levels; course evaluation is used as a standard; students will be absolutely tested even though there are difficulties. Exam result evaluation is to evaluate the students' learning level and cognitive capability. Therefore, "fairness" and "justice" are truly realized in test to reflect the learning situation of the students.

\section{Conclusion}

In the physical education, the application of hierarchical teaching method can promote the students' physical and mental health development. This requires students to change learning ideas and enhance the interest in sports; teachers must change the teaching methods and realize the optimal development of the physical education in colleges and universities using the flexible, 
diverse, and targeted hierarchical teaching method.

\section{References}

[1] Zhiyun Chen. Discussion on the Practice of Dynamic Hierarchical Teaching Model in the English Education of Local Undergraduate Colleges [J]. Chinese Journal of Education (Foreign Language Teaching), 2015 (1): 108-109.

[2] Xiao-bo Gao. The Application of Hierarchical Teaching Model to the Ideological and Political Theory Course Teaching Practice [J]. Science Tribune, 2014 (7): 34-40.

[3] Jun-min liu. Study on the Innovation for the Implementation of Sports Club Hierarchical Teaching Model—Shaanxi Vocational
College of Industry and Commerce Is Taken for Example [J]. Journal of Contemporary Sports Science and Technology, 2014 (16): 45-46.

[4] Yanci Hu. Discussion on the Rationality of the Application of the Task Teaching Method under the Hierarchical Teaching Model-Study on College English Teaching under the Chinese-Foreign Cooperation Educational Model [J]. Urban Family Education, 2013 (12): 34-35.

[5] Chun-xiang Guo, Qing Wang. Study on the Practice of Hierarchical Teaching Model in the Applied Mathematics Course Reform in Higher Vocational Colleges-Changzhou Mechanical and Electrical Professional Technology Institute Is Taken for Example [J]. Journal of Vocational Education, 2013 (12): 21-23. 